\title{
Biologia floral de Cleistes macrantha (Barb. Rodr.) Schltr. (Orchidaceae: Vanilloideae: Pogoniinae)
}

\author{
EMERSON R. PANSARIN ${ }^{1}$
}

(recebido: 22 de maio de 2002; aceito: 20 de novembro de 2002)

\begin{abstract}
Floral biology of Cleistes macrantha (Barb. Rodr.) Schltr. (Orchidaceae: Vanilloideae: Pogoniinae)). Cleistes macrantha (Barb. Rodr.) Schltr. is widely distributed in Atlantic rain forests in south and southeastern Brazil, occurring in anthropogenic disturbed areas and in "restinga" vegetation. Aspects of the floral biology of C. macrantha were investigated in the Intervales nature reserve, in the interior of São Paulo state. This species offers nectar as reward and is pollinated principally by bumblebees. The nectar is secreted before the anthesis of the flowers, with no posterior secretion. Hermit hummingbirds can also act as pollinators. A previous visit of a bumblebee, however, is necessary for pollen deposition on their bills. Bumblebees are responsible for most cross-pollinations. The hummingbirds perform mainly self-pollination. Preliminary treatments reveal that $C$. macrantha is self-compatible, but a pollinator is necessary for successful pollination. In spite of the self-compatibility observed, ecological factors favor cross-pollination in this species. This study makes too, a comparison of the floral biology of $C$. macrantha with what is known about the genera of the North American-Asiatic clade in Pogoniinae.
\end{abstract}

Key words - Cleistes, floral biology, Orchidaceae, Pogoniinae, pollination

RESUMO - (Biologia floral de Cleistes macrantha (Barb. Rodr.) Schltr. (Orchidaceae: Vanilloideae: Pogoniinae)). Cleistes macrantha (Barb. Rodr.) Schltr. distribui-se amplamente em regiões de Mata Atlântica do sul e sudeste brasileiros, onde ocorre em áreas perturbadas e em restinga. Aspectos da biologia floral de C. macrantha foram investigados na região de Intervales, no interior do Estado de São Paulo. Esta espécie oferece néctar como recompensa e é polinizada principalmente por espécies de abelhas do gênero Bombus. O néctar é secretado antes da antese, não havendo secreção após a abertura das flores. Beija-flores do gênero Phaethornis também podem atuar como polinizadores. No entanto, é necessária uma prévia visita de Bombus spp. para que possa ocorrer a deposição de pólen no bico dos beija-flores. Abelhas Bombus são responsáveis pela realização da maioria das polinizações cruzadas. Os beija-flores realizam principalmente autopolinização. Tratamentos preliminares revelam que $C$. macrantha é auto-compatível, mas dependente de um agente polinizador. Apesar da auto-compatibilidade, fatores ecológicos favorecem a polinização cruzada para a espécie. Este estudo faz, ainda, uma comparação da biologia floral de C. macrantha com o que é conhecido sobre os gêneros pertencentes ao clado norte-americano-asiático em Pogoniinae.

Palavras-chave - Biologia floral, Cleistes, Orchidaceae, Pogoniinae, polinização

\section{Introdução}

A subtribo Pogoniinae (Orchidaceae: Vanilloideae), um grupo monofilético segundo Cameron et al. (1999), compreende cinco gêneros distribuídos entre as Américas do Norte e do Sul, e oeste da Ásia (Cameron \& Chase 1999). Dentre esses gêneros, inclui-se Cleistes L.C. Rich. ex Lindl., o maior dentro da subtribo, com 70 espécies descritas. O gênero Cleistes apresenta seu centro de diversidade na América do Sul, com apenas uma espécie, C. rosea Lindl., ocorrendo até a América Central (Cameron \& Chase 1999). As espécies sul e centro-americanas de Cleistes formam um grupo monofilético. A inclusão de $C$. divaricata, que ocorre

1. Universidade Estadual de Campinas, Instituto de Biologia, Departamento de Botânica, Caixa Postal 6109, 13083-970 Campinas, SP, Brasil. pansarin@unicamp.br na América do Norte, na análise, torna o gênero parafilético (Cameron \& Chase 1999). C. divaricata é mais proximamente relacionada com os gêneros norteamericanos Isotria e Pogonia do que com os demais representantes sul-americanos do gênero Cleistes (Cameron \& Chase 1999).

Dados sobre polinização em Pogoniinae restringem-se ao clado norte-americano-asiático. Pogonia ophioglossoides (L.) Jussieu é polinizada por abelhas operárias do gênero Megachile e rainhas e operárias do gênero Bombus. Nessa espécie, o polinário, que é farináceo como nos demais gêneros em Pogoniinae (Cameron et al. 1999), fica aderido à face frontal da cabeça das abelhas (Thien \& Marcks 1972). Isotria medeoloides (Pursh) Raf. reproduz-se através de autopolinização espontânea e I. verticillata (Muhl. ex Willd.) Raf. é polinizada por pequenas abelhas pertencentes às famílias Halictidae, Anthophoridae e 
Adrenidae, nas quais os grãos de pólen ficam depositados na face dorsal do tórax (Mehrhoff 1983). Cleistes divaricata (L.) Ames, que ocorre no oeste da Virginia, é polinizada por abelhas operárias dos gêneros Megachile e Bombus, nas quais o pólen é depositado na face dorsal do tórax (Gregg 1989). Nessa espécie, os polinizadores são atraídos por engano, pois as flores não oferecem recompensa alguma (Gregg 1989). Assim como em Cleistes divaricata, Dressler (1993) relata que em Pogonia e Isotria os polinizadores são atraídos por engano devido à presença, no labelo, de tricomas que imitam pólen. Thien \& Marcks (1972), no entanto, observaram o acúmulo de uma pequena quantidade de néctar na base do labelo de $P$. ophioglossoides.

Dentre os representantes sul-americanos do gênero Cleistes, encontra-se C. macrantha, incluída na seção (como "centro de espécie") Cleistes speciosa, por Hoehne (1940). C. macrantha é uma espécie amplamente distribuída entre os Estados de Santa Catarina e Rio de Janeiro, ocorrendo principalmente em regiões de Mata Atlântica. A espécie é comumente encontrada em regiões de restinga e áreas perturbadas, principalmente ao longo de estradas e rodovias, em barrancos úmidos na Serra do Mar. Em locais perturbados, ocorre principalmente em associação com Gleichenia sp. No Estado de São Paulo, C. macrantha pode ser encontrada também no interior, mas sempre está associada com regiões perturbadas, ocorrendo em barrancos úmidos.

A importância dos polinizadores na evolução da família Orchidaceae é refletida na complexidade das características dos mecanismos de polinização (Garay 1960, Van der Pijl \& Dodson 1966). Muitas espécies em Orchidaceae são auto-compatíveis, no entanto, a polinização cruzada parece ser a regra (Van der Pijl \& Dodson 1966). Algumas características podem favorecer a polinização cruzada em Orchidaceae. Essas características podem ser ecológicas como, por exemplo, a sincronia de floração com a emergência dos polinizadores (Ackerman 1981, Boyden 1982), ou o sincronismo de floração entre populações, no caso de plantas que produzem poucas flores por inflorescência (Medley 1979, Pansarin 2000). A produção de flores em seqüência na inflorescência e alguns tipos de mecanismos florais são muito difundidos em orquídeas e também podem favorecer a polinização cruzada de muitas espécies (revisão em Catling \& Catling 1991).

Pouco é conhecido sobre a biologia reprodutiva em Pogoniinae (Luer 1975). Dados sobre polinização e biologia floral para esta subtribo estão restritos às espécies norte-americanas, não existindo, até o momento, estudos com espécies que ocorrem nas Américas do Sul e Central. O presente trabalho é o primeiro sendo realizado com um representante sulamericano em Pogoniinae. No presente trabalho foram investigados aspectos da biologia floral de Cleistes macrantha, identificados os fatores que previnem a autopolinização na espécie e realizados tratamentos preliminares para verificação do sistema reprodutivo. Os resultados obtidos neste estudo foram discutidos a partir das informações existentes para as espécies norteamericano-asiáticas.

\section{Material e métodos}

Os estudos foram realizados em uma área de mata

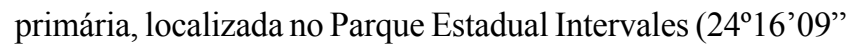
S e $48^{\circ} 24^{\prime} 56^{\prime \prime}$ W), sul do Estado de São Paulo. O parque possui 49.000 ha de Mata Atlântica e está localizado entre os municípios de Guapiara, Ribeirão Grande, Sete Barras, Eldorado e Iporanga. O presente trabalho foi desenvolvido na área localizada no município de Ribeirão Grande.

O Parque Estadual Intervales localiza-se na Serra de Paranapiacaba. Nessa região, as escarpas serranas estão recuadas até cerca de $100 \mathrm{~km}$ da orla litorânea, abrindo em um amplo fronte erosivo de aspecto montanhoso (Almeida 1974). A planície entre a Serra de Paranapiacaba e o litoral é formada pelo Vale do Rio Ribeira. A altitude do Parque varia de 60 a $1.100 \mathrm{~m}$, sendo que o presente estudo foi realizado em uma altitude de $900 \mathrm{~m}$. A precipitação anual é de cerca de $1.800 \mathrm{~mm}$, apresentando baixa sazonalidade. A temperatura média anual oscila entre 17 e $19^{\circ} \mathrm{C}$. A região sofre influência do clima mesotérmico brando, com estação subseca. As chuvas ocorrem durante o ano todo, mas é possível determinar uma estação mais chuvosa, de outubro a março e outra, subseca, de abril a setembro (Nimer 1989).

Em Intervales foram realizadas observações e o registro fotográfico do processo de polinização de Cleistes macrantha. As observações foram realizadas entre os dias 3 e 6 de março de 2001, período em que ocorreu o pico de florada mais significativo dentro da população. As observações estenderam-se das $6: 30 \mathrm{~h}$ às $17: 30 \mathrm{~h}$, totalizando 33 horas. No decorrer das observações, visitantes florais foram capturados para posterior identificação. Não foram realizadas observações noturnas. A eventual ocorrência de visitas noturnas foi investigada através da conferência, pela manhã, de flores marcadas na tarde anterior. Observações adicionais foram realizadas nos anos de 1999 e 2000, nos municípios de Caraguatatuba e Ubatuba. Durante as visitas ao campo, flores frescas foram fixadas em álcool $70 \%$ para investigação da morfologia floral. As peças florais foram desenhadas com auxílio de um estereomicroscópio acoplado a câmera clara. $\mathrm{O}$ material testemunho está depositado no herbário da Universidade Estadual de Campinas (UEC) - E.R. Pansarin 857. Os beija-flores observados e fotografados e o 
material entomológico coletado foram identificados através da comparação com espécimes depositados no Museu de História Natural da Universidade Estadual de Campinas (ZUEC).

Os tratamentos para verificação do sistema reprodutivo foram realizados em casa de vegetação, na Universidade Estadual de Campinas. Devido à escassez de flores produzidas pelos indivíduos, foram utilizadas apenas quatro flores por tratamento no dia em que ocorreu a antese, e outras quatro flores por tratamento no segundo dia após a antese. Os tratamentos realizados foram: polinização cruzada, autopolinização manual, emasculação e autopolinização espontânea.

\section{Resultados e Discussão}

$\mathrm{Na}$ reserva de Intervales, Cleistes macrantha ocorre em barrancos ao longo das estradas, em locais perturbados com predominância de Gleichenia sp. As plantas são eretas, com $40-80 \mathrm{~cm}$ de altura e produzem até cinco flores ressupinadas por inflorescência (figura 1A). A inflorescência é folhosa e representa um contínuo do caule aéreo (figura 1A). As flores medem cerca de $6-8 \mathrm{~cm}$ de comprimento (figura $1 \mathrm{~A}-\mathrm{B}$ ) e apresentam diversos tons de rosa (figura 2A). As sépalas são linear-lanceoladas e de consistência carnosa. As pétalas são espatuladas e membranáceas (figura 1C). O labelo é trilobado, róseo-esbranquiçado com estrias e ápice vináceos (figuras 1C, 2B). O lobo apical do labelo varia desde arredondado até agudo. A forma dos lobos laterais também é muito variável, podendo ser desde arredondados até truncados. A crista do labelo é formada por estrias brancas com ápice amarelo. $\mathrm{Na}$ base do labelo existem duas glândulas esféricas, que secretam néctar. O néctar fica acumulado na câmara nectarífera, um espaço delimitado por uma elevação da base da crista do labelo (figura $1 \mathrm{~F}$ ). A coluna mede cerca de $5 \mathrm{~cm}$ de comprimento (figura 1D-E), é branca e paralela ao labelo. No ápice da coluna localizase a antera, que é versátil (figura 1D-E) com duas polínias amarelas, de consistência farinácea. A superfície estigmática apresenta papilas hialinas e uma fenda em forma de "U" na porção basal (figura 1E).

As flores de Cleistes macrantha apresentam antese diurna, desabrochando ao amanhecer. Três dias após a antese, ocorre o processo de fenecimento das flores. Antes da antese, o néctar já está totalmente secretado, não havendo secreção posterior. A antese das flores é sincrônica dentro da mesma população, com a maioria dos indivíduos florescendo em um mesmo dia. Existe um pico principal de floração, quando ocorre a antese da maioria das flores na população. Outros picos menos intensos podem ocorrer. Poucos botões, entretanto, ainda permanecem fechados após o primeiro pico de floração. Não foi possível correlacionar a ocorrência do pico de floração com nenhum fator ambiental, tal como chuva, já que podem ser observados picos de floração tanto em dias ensolarados como chuvosos. A ocorrência do próximo pico de florada também é imprevisível e pode ocorrer em um intervalo de uma semana até cerca de 20 dias. Outras orquídeas podem apresentar um padrão semelhante de ocorrência de picos de floração. Em Psilochilus modestus Barb. Rodr., foi observado que toda a população floresce e as flores duram apenas um dia. Como em C. macrantha, o sincronismo de floração em $P$. modestus não pode ser relacionado com nenhum fator ambiental (Pansarin 2000). Medley (1979) observou sincronismo de floração em Triphora trianthophora (Sw.) Rydb., na qual centenas de plantas florescem no mesmo dia e as flores fenescem no dia posterior à antese. Em T. trianthophora o sincronismo de floração parece ser mediado pela chuva (Medley 1979).

Flores de Cleistes macrantha são visitadas por espécies de abelhas operárias do gênero Bombus, por borboletas da família Hesperiidae e por duas espécies de beija-flores do gênero Phaethornis (Trochilidae: Phaethorniinae). Através da conferência das flores marcadas, não foram detectados visitantes noturnos para C. macrantha.

Os principais agentes polinizadores de Cleistes macrantha são abelhas do gênero Bombus. Foram observadas duas espécies de Bombus como polinizadores: Bombus (Fervidobombus) atratus Franklin 1913, a espécie mais freqüente como polinizador de $C$. macrantha na área estudada (figura 2B-C) e Bombus (Fervidobombus) brasiliensis Lepeletier 1835. Ambas visitam a maioria dos indivíduos com flores disponíveis ao longo das margens da estrada. A atividade das abelhas inicia-se por volta das 7:30 h e se estende até cerca de 13:00 h. Cada abelha visita de uma a duas flores por inflorescência, e cada uma delas com duração de cerca de 10 segundos. A visita inicia-se com o animal pousando no ápice do labelo da flor. Em seguida, a abelha dirige-se para a base do labelo para acessar o néctar (figura 2B). Como a antera é versátil, a abelha não toca o pólen ao entrar no estreito tubo formado pelo labelo. Apenas quando ela se afasta para abandonar a flor, esbarra com a região dorsal do tórax na antera, desarticulando-a. Nesse momento o pólen é depositado no escuto do animal (figura 2C). Após a abelha abandonar a flor, a antera 


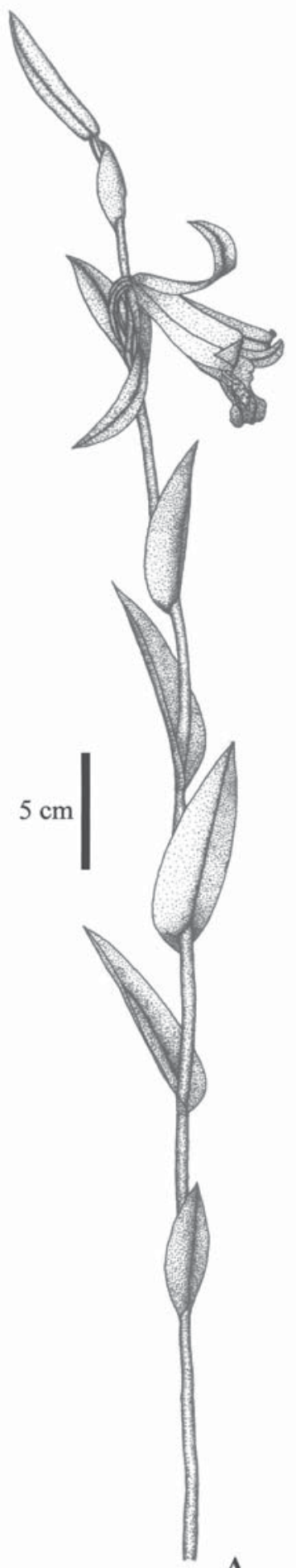

A
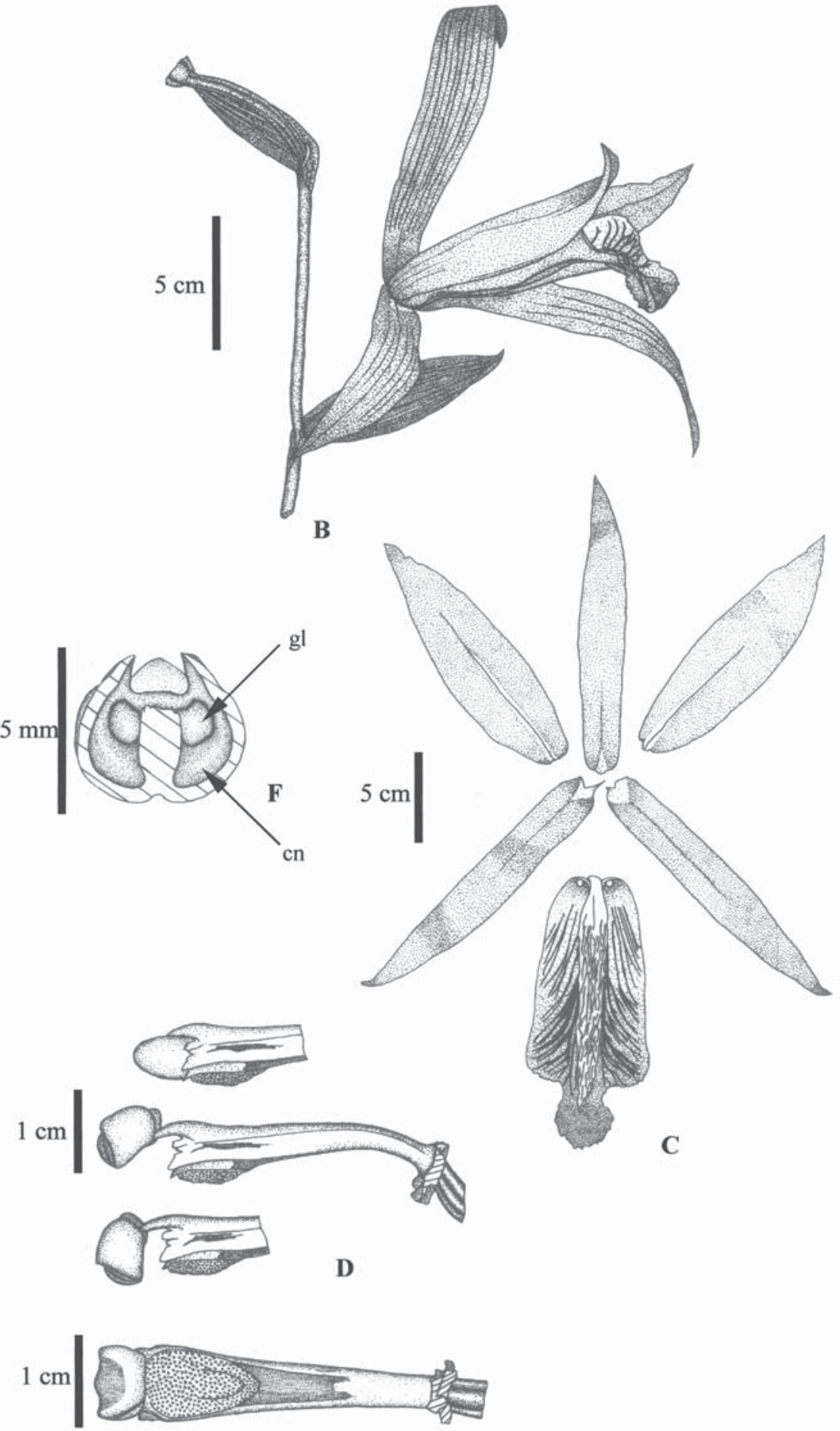

$\mathbf{E}$

Figura 1. Cleistes macrantha. A. Hábito. B. Flor. C. Perianto. D. Coluna em vista lateral, mostrando a seqüência de desarticulação da antera. E. Coluna em vista ventral. F. Base do labelo em corte transversal, mostrando as duas glândulas (gl) e as câmaras nectaríferas (cn).

Figure 1. Cleistes macrantha. A. Habit. B. Flower. C. Perianth. D. Column, lateral view, showing the anther disarticulation sequence. E. Column, ventral view. F. Lip basis in cross section showing the two glands (gl) and the nectariferous chambers (cn). 
permanece desarticulada, pois o espaço que a separa da crista do labelo é muito pequeno e ela fica apoiada sobre a crista. A figura 1D mostra, ordenadamente, a seqüência de desarticulação da antera. No momento em que ocorre outra visita por Bombus spp., a antera volta à posição inicial, de modo que a abelha apenas consegue depositar pólen nas papilas do estigma. A abelha somente receberá o pólen quando abandonar a flor, ao desarticular novamente a antera. Esse procedimento evita que, durante uma única visita, a abelha leve ao estigma, pólen da mesma flor, favorecendo, portanto, a polinização cruzada. Algumas vezes, as abelhas que saem das flores com o escuto impregnado com pólen iniciam um processo de limpeza, coletando o pólen residual aderido aos seus corpos e transferindo-o para as corbículas. Processo semelhante de coleta indireta de pólen como conseqüência da limpeza do pólen que fica aderido ao corpo dos polinizadores, foi observado em C. divaricata (Gregg 1991b).

As visitas por Bombus spp. ocorrem apenas nos dois primeiros dias após a antese, enquanto as flores ainda possuem néctar. Nem todas as flores têm seu néctar esgotado logo no primeiro dia. Em algumas flores, no segundo dia após a antese, um pouco de néctar ainda permanece, sendo aproveitado pelas abelhas. Mesmo que apenas algumas flores apresentem néctar, a maioria delas é visitada. As abelhas permanecem apenas cerca de dois segundos nas flores que não apresentam néctar. Apesar de Bombus spp. visitarem as flores de C. macrantha no segundo dia após a antese, transferindo pólen entre os indivíduos, não acarreta na formação de frutos, pois o estigma permanece receptivo apenas no primeiro dia.

Duas espécies de beija-flores do gênero Phaethornis, Phaethornis eurynome Lesson 1832 (figura 2D) e Phaethornis squalidus Temminck 1822, foram observadas como visitantes florais de Cleistes macrantha. Ambas as espécies geralmente visitam apenas uma ou duas flores disponíveis na população e nunca foram observadas visitando os indivíduos com flores disponíveis ao longo da estrada, como ocorre com as espécies de Bombus. Na ocasião, foi observado que ambas as espécies de Phaethornis apresentaram comportamento "trapliner" na reserva Intervales. P. eurynome foi observado retornando aos mesmos indivíduos de Vriesea sp. (Bromeliaceae) e Justicia sp. (Acanthaceae) em intervalos de aproximadamente $1 \mathrm{~h}$ e 10 min. e P. squalidus retornando apenas em Vriesea sp., em intervalos de 30-40 min. As flores de C. macrantha são visitadas somente quando um beija-flor já visitou flores de Vriesea sp. ou Justicia sp. que estão próximas à população. Espécies do gênero Phaethornis são conhecidas por serem polinizadores eficientes e "trapliners", geralmente visitando flores em intervalos regulares (Feinsinger \& Colwell 1978, Stiles 1985, Sazima et al. 1995, 1996). Claramente a morfologia de C. macrantha, principalmente o diâmetro e comprimento formado pelo tubo do labelo, está adaptada para a polinização por Bombus spp. (figura 2B). Ambas as espécies de Phaethornis, entretanto, podem atuar como polinizadores de C. macrantha, em condições especiais. Os beija-flores, por possuírem bico muito estreito em relação ao espaço formado pela antera e a crista do labelo, não conseguem desarticular a antera das flores de C. macrantha, como as espécies de Bombus observadas. Entretanto, se a flor foi previamente visitada por um indivíduo de Bombus, a antera permanece desarticulada. Quando um beija-flor visita a flor, após a prévia visita de uma abelha Bombus, ele pode empurrar, com o bico, o pólen da própria flor até o estigma e promover a autopolinização. No momento em que remove o bico da flor, também pode receber pólen, que, posteriormente, será levado a outra flor, em uma próxima visita. Se o beija-flor, portando pólen em seu bico, visitar uma flor com antera intacta, ele poderá realizar polinização cruzada.

Várias espécies de borboletas da família Hesperiidae visitam flores de Cleistes macrantha. As visitas ocorrem principalmente nas horas mais quentes do dia, quando os raios de sol atingem as flores. Lepidópteros com probóscides mais longas conseguem acessar o néctar apenas pousando no ápice do labelo, sem entrar na flor (figura 2E). Entretanto, espécies com probóscides mais curtas que o comprimento do labelo, precisam entrar parcialmente na flor para obter o néctar (figura $2 \mathrm{~F}$ ). Em nenhum dos casos foram observados lepidópteros tocando os órgãos reprodutivos das flores. Em C. macrantha, aparentemente, os lepidópteros atuam apenas como pilhadores de néctar.

Os tratamentos, embora preliminares, realizados em casa de vegetação, revelam que Cleistes macrantha é auto-compatível, mas dependente de um agente polinizador. Todas as quatro flores utilizadas nas autopolinizações manuais e polinizações cruzadas promoveram a formação de frutos. Nenhuma das quatro flores intactas ou emasculadas chegou a promover frutificação. Somente as flores que recebem pólen no primeiro dia da antese chegam a formar frutos. Assim como C. macrantha, os demais representantes norteamericanos de Pogoniinae são auto-compatíveis. Do mesmo modo, como observado em C. macrantha, todas 


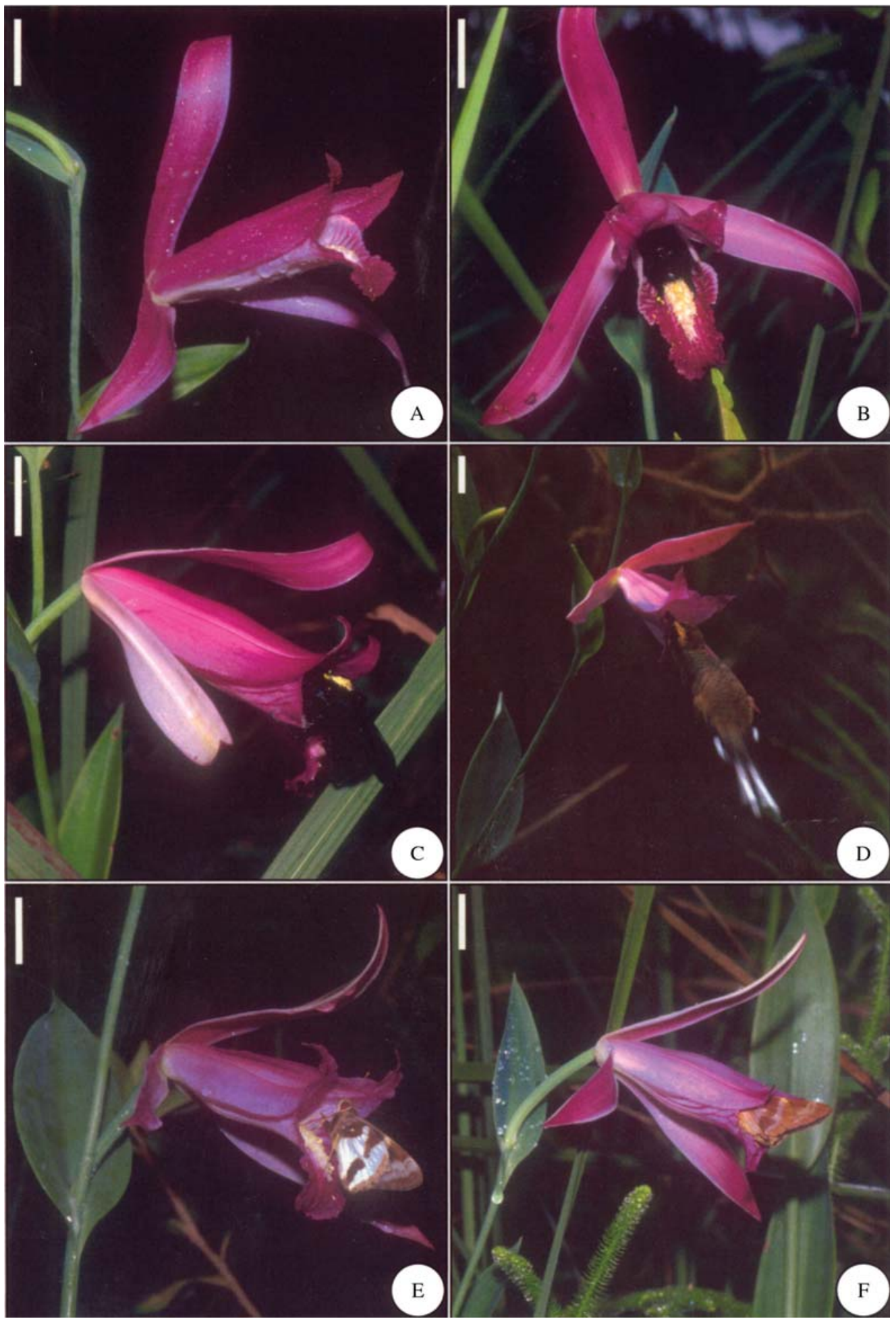

Figura 2. Cleistes libonii. A. Flor. B. Bombus atratus contactando a antera da flor com o escuto enquanto obtém néctar na base do labelo. C. B. atratus saindo da flor com o escuto coberto por pólen. D. Phaethornis eurynome obtendo néctar na base do labelo. E. Hesperiidae obtendo néctar apenas com a probóscide dentro da flor. F. Hesperiidae obtendo néctar com o corpo parcialmente dentro da flor. Barras de escala $=2 \mathrm{~cm}$.

Figure 2. Cleistes macrantha. A. Flower. B. Bombus atratus touching the anther with the scutum while collecting nectar from the base lip. C. B. atratus leaving the flower with its scutum spreaded by pollen. D. Phaethornis eurynome collecting nectar from the base of the lip. E. A skipper collecting pollen with only its proboscis inside the flower. A skipper collecting nectar with its body partly inside of the flower. Scale bars $=2 \mathrm{~cm}$. 
as espécies norte-americanas, com exceção da autógama Isotria medeoloides, são dependentes de um agente polinizador (Thien \& Marcks 1972, Mehrhoff 1983, Gregg 1989).

Apesar de Cleistes macrantha ser auto-compatível, alguns fatores podem favorecer a ocorrência de polinização cruzada nessa espécie. Cada indivíduo de C. macrantha produz poucas flores por inflorescência, existe um preciso sincronismo de floração dentro da população e o estigma permanece receptivo por um único dia. A combinação desses fatores pode favorecer enormemente a polinização cruzada na população. Assim como observado para C. macrantha, em Triphora trianthophora (Medley 1979) e Psilochilus modestus (Pansarin 2000), a polinização cruzada é favorecida pela escassez de flores produzidas por inflorescência e pelo sincronismo de floração.

Em Cleistes macrantha, como o polinário tem consistência farinácea e não é removido em pacotes, como acontece na maioria das Orchidaceae (Dressler 1981, 1993), apenas uma pequena quantidade de pólen é depositada sobre o polinizador em cada visita. Em Cleistes divaricata, a antera, que é versátil como em C. macrantha, pode depositar pólen por diversas vezes ao corpo dos polinizadores. A quantidade de pólen depositada, entretanto, decresce com as visitas subseqüentes (Gregg 1991a). A deposição de pólen em pequenas quantidades nos polinizadores permite que mais de um animal possa receber pólen de uma única flor, o que pode reduzir a perda de pólen se a flor for visitada por um polinizador ineficiente. Na maioria das Orchidaceae, nas quais as polínias são removidas em uma única visita, a remoção do polinário por um polinizador ineficiente pode resultar em uma grande perda de pólen (Tremblay 1992).

Dressler (1993) relata que as espécies pertencentes aos gêneros Cleistes, Isotria e Pogonia atraem polinizadores por engano, para os quais os tricomas existentes no labelo simulam pólen. Curiosamente, em Cleistes divaricata, Isotria verticillata e Pogonia ophioglossoides, assim como em todos os representantes sul-americanos do gênero Cleistes, esses tricomas estão concentrados na porção mais apical do labelo, enquanto na altura da antera, essas estruturas estão ausentes. Dessa forma, se as abelhas coletassem os tricomas como se fossem grãos de pólen, elas não precisariam se dirigir à base do labelo para obterem alimento e, conseqüentemente, não contactariam os órgãos reprodutivos da flor. Thien \& Marcks (1972) observaram que os tricomas branco-amarelados existentes no labelo de $P$. ophioglossoides são as estruturas que mais absorvem luz ultravioleta na flor, sendo a região mais visível para as abelhas. Esses mesmos autores indicam que $P$. ophioglossoides, além dos tricomas no labelo, também oferece pequenas quantidades de néctar aos insetos. Do mesmo modo, Guignard (1879 apud Thien \& Marcks 1972) relata que após rasparem a crista do labelo, as abelhas se dirigem à base dessa estrutura, na qual uma pequena quantidade de néctar fica acumulada. Em P. ophioglossoides, como em C. macrantha, e outras espécies sul-americanas como C. aphylla (Barb. Rodr.) Schltr., C. castanoides Hoehne, C. exilis Hoehne e C. gracilis (Barb. Rodr.) Schltr., os tricomas do labelo podem, simplesmente, estar atuando como guias de néctar e não como fontes de alimento como proposto por Dressler (1993). Assim, a natureza das recompensas florais das espécies norteamericanas de Pogoniinae deve ser melhor investigada, pois é provável que os tricomas do labelo dessas espécies são apenas guias de néctar, como observado em espécies sul-americanas de Cleistes. $\mathrm{O}$ fato de, em Cleistes, o néctar já estar totalmente secretado antes da antese, pode trazer interpretações errôneas se a biologia floral de uma determinada espécie não for minuciosamente investigada. Fagnani (2001) relata que C. macrantha não oferece néctar, sendo polinizada por engano, por abelhas que procuram alimento. Muito provavelmente, pelo menos no que se refere às espécies sul-americanas de Cleistes, a estratégia de engano dos polinizadores não se aplica e as considerações errôneas, até agora realizadas, podem ser conseqüência de observações em flores abertas há mais de um dia, cujo néctar, provavelmente, já havia sido esgotado pelos visitantes florais.

Todas as espécies de Cleistes que ocorrem nas Américas do Sul e Central apresentam nectários glandulares na base do labelo e a presença dessas estruturas, provavelmente, representa uma sinapomorfia para o clado sul-centro-americano do gênero (Pansarin, dados não publicados). Nas espécies norte-americanas de Isotria (Mehrhoff 1983), em Cleistes divaricata (Gregg 1989) e em Pogonia ophioglossoides, entretanto, esses nectários glandulares estão ausentes. A presença de nectários nos gêneros norte-americanos precisa ser melhor investigada através de estudos anatômicos, uma vez que foi observada a presença de néctar em P. ophioglossoides (Thien \& Marcks 1972), mas nectários glandulares estão ausentes nesta espécie.

Assim como observado para Cleistes macrantha, C. divaricata (Gregg 1989), Isotria verticillata (Mehrhoff 1983) e Pogonia ophioglossoides (Thien \& Marcks 1972), outras espécies sul-americanas de 
Cleistes, como C. aphylla, C. castanoides, C. exilis e C. gracilis também são polinizadas por abelhas (Pansarin, dados não publicados). Assim, com exceção da autógama I. medeoloides (Mehrhoff 1983), abelhas parecem ser os principais vetores de pólen em Pogoniinae, estando presentes em todos os gêneros até agora investigados. Duckeella, no entanto, um gênero endêmico da região amazônica e irmão do restante da subtribo Pogoniinae (Cameron \& Chase 1999), é completamente desconhecido com relação aos aspectos de sua biologia reprodutiva e polinização. O avanço das pesquisas com Duckeella e representantes das demais seções do gênero Cleistes poderão propiciar um maior entendimento sobre aspectos da hipótese filogenética de Pogoniinae e, conseqüentemente, sobre a evolução da polinização da subtribo.

Agradecimentos - $\mathrm{O}$ autor agradece ao Dr. Volker Bittrich pela revisão crítica, a Profa. Maria do Carmo E. Amaral pelas sugestões dadas, à diretoria do Parque Estadual Intervales pela autorização concedida para realização das observações de campo e à Fapesp pelo financiamento do projeto (Processo n. 00/11015-9).

\section{Referências bibliográficas}

ACKERMAN, J.D. 1981. Pollination biology of Calypso bulbosa var. occidentalis (Orchidaceae): a food deception system. Madroño 28:101-110.

ALMEIDA, F.F.M. 1974. Fundamentos Geológicos do relevo paulista. Série teses e monografias. Instituto de Geografia da Universidade de São Paulo, São Paulo, v.14.

BOYDEN, T.C. 1982. The pollination biology of Calypso bulbosa var. americana (Orchidaceae): initial deception of bumblebee visitors. Oecologia 55:178-184.

CAMERON, K.M. \& CHASE, M.W. 1999. Phylogenetic relationships of Pogoniinae (Vanilloideae, Orchidaceae): an herbaceous example of the eastern North America eastern Asia phytogeographic disjunction. Journal of Plant Research 112:317-329.

CAMERON, K.M., CHASE, M.A., WHITTEN, W.M., KORES, P.J., JARRELL, C., ALBERT, V.A., YUKAWA, T., HILLS, H.G. \& GOLDMAN, D.H. 1999. A phylogenetic analysis of the Orchidaceae: evidence from rbcL nucleotide sequences. American Journal of Botany 86:208-224.

CATLING, P.M. \& CATLING, V.R. 1991. A synopsis of breeding systems and pollination in north American orchids. Lindleyana 6:187-210.

DRESSLER, R.L. 1981. The orchids: natural history and classification. Harvard University Press, Cambridge.

DRESSLER, R.L. 1993. Phylogeny and classification of the orchid family. Cambridge University Press, Cambridge.
FAGNANI, M.P.K. 2001. Orquídeas da cidade do Rio de Janeiro. Orquidário 14:2-4.

FEINSINGER, P. \& COLWELL, R.K. 1978. Community organization among neotropical nectar-feeding birds. American Zoologist 18:779-795.

GARAY, L.A. 1960. On the origin of the Orchidaceae. Botanical Museum Leaflets of Harvard University 19:57-96.

GREGG, K.B. 1989. Reproductive biology of the orchid Cleistes divaricata (L.) Ames var. bifaria Fernald growing in West Virginia meadow. Castanea 54:57-78.

GREGG, K.B. 1991a. Reproductive strategy of Cleistes divaricata (Orchidaceae). American Journal of Botany 78:350-360.

GREGG, K.B. 1991b. Defrauding the deceitful orchid: pollen collection by pollinators of Cleistes divaricata. Lindleyana 6:214-220.

HOEHNE, F.C. 1940. Orchidaceae. In Flora Brasílica (F.C. Hoehne, ed.). Instituto de Botânica, São Paulo, v.12, fasc.1, p.1-254, tab. 1-153.

LUER, C.A. 1975. The native orchids of United States and Canada. New York Botanical Garden, New York.

MEDLEY, M.E. 1979. Some aspects of the life story of Triphora trianthophora (Sw.) Rydb. (Three birds orchid) with reference to its pollination. PhD Thesis, St Andrews University, St Andrews.

MEHRHOFF, L.A. 1983. Pollination in the genus Isotria (Orchidaceae). American Journal of Botany 70:1444-1453.

NIMER, E. 1989. Climatologia do Brasil. 2 ed. IBGE, Rio de Janeiro.

PANSARIN, E.R. 2000. Biologia reprodutiva e morfologia floral de espécies de Orchidaceae em diferentes ambientes no Estado de São Paulo. Dissertação de mestrado, Universidade Estadual de Campinas, Campinas.

SAZIMA, I., BUZATO, S. \& SAZIMA, M. 1995. The saw billed hermit Ramphodon naevius and its flowers in southeastern Brazil. Journal of Ornithology 136:195-206.

SAZIMA, I., BUZATO, S. \& SAZIMA, M. 1996. An assemblage of hummingbird-pollinated flowers in a Montane Forest in Southeastern Brazil. Botanica Acta 109:149-160.

STILES, F.G. 1975. Ecology, flowering phenology, and hummingbird pollination of some Costa Rican Heliconia species. Ecology 56:323-351.

THIEN, L.B. \& MARCKS, B.G. 1972. The floral biology of Arethusa bulbosa, Calopogon tuberosus, and Pogonia ophioglossoides (Orchidaceae). Canadian Journal of Botany 50:2319-2325.

TREMBLAY, R.L. 1992. Trends in pollination ecology of the Orchidaceae: evolution and systematics. Canadian Journal of Botany 70:642-650.

VAN DER PIJL, L. \& DODSON, C.H. 1966. Orchid flowers: Their pollination and evolution. University of Miami Press, Coral Gables. 